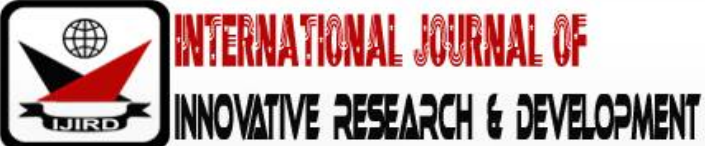

ISSN 2278 - 0211 (Online)

\section{Analysis of Gender Preference of Commuters among Okadariders in Auchi: A Survey Based Study, Nigeria}

\begin{tabular}{|c|}
\hline Asunogie, $\mathbf{\text { O.F }}$ \\
Lecturer, Department of Urban and Regional Planning, \\
Auchi Polytechnic, Auchi, Edo state, Nigeria \\
Eboreme, L \\
Lecturer, Department of Urban and Regional Planning, \\
Auchi Polytechnic, Auchi, Edo state, Nigeria \\
Osagioduwa, M \\
Lecturer, Department of Urban and Regional Planning, \\
Auchi Polytechnic, Auchi, Edo state, Nigeria \\
Ojeh, P.A.P \\
Lecturer, Department of Estate Management and Valuation, \\
Auchi Polytechnic, Auchi, Edo state, Nigeria
\end{tabular}

\section{Abstract:}

The introduction of motorcycle popularly called 'Okada' as an alternative mode of transport in urban centers was prompted by the high cost, bad state of roads and others inevitable transport service provisions which impacted negatively on economic activities and the relative immobility of the urban populace. Thus, the choice of motorcycle to carry passenger tends to favor men. This makes women gender-biased by the operators, a basis for the analysis of gender preference of commuter by Okada operatives in Auchi, Estako-west local government area of Edo state with the aim of analyzing the gender preference of commuters among Okada riders in Auchi. The research design was strictly survey and observatory with a research population of Okada riders estimated, using a simple random sampling technique. Based on the findings, the study concluded that okada riders in Auchi are all men that are mostly married with daily earnings between $\$ 1000$ - $\$ 5000$; that there is clear evidence of preference against females by okada operators/riders but this is due to underpinning factors ranging from weight, extra luggage among others and therefore recommended that Environmental and sustainability issues, as well as gender perspective need to be fully integrated into all transport related policy-making; That Government should introduce participatory, inclusive transport planning methodologies in other to incorporate the social gender of transport and travel need; there is a need for more inclusive gender sensitive transport system in the study area among others.

Keywords: Gender, preference, Okada riders, female commuters, alternative mode, transport

\section{Introduction}

Transport can be seen as the movement of people, animals and goods from one location to another. For many years, public transport has been viewed as an inevitable need in several parts of the world (Cervero and Golub2007). The rapid increase in urban population and automobile ownership and usage has resulted in urban transportation problems of achieving the appropriate standard of urban mobility. This is because Mobility is an important element of a community and it is mainly dependent on automobile in most developing countries or cities, (Fernando and Porter, 2002). To address these problems, new modes or means have emanated over the years, including the introduction of 'Okada' into public space as a means of transport. The introduction of motorcycle popularly called 'Okada' as an alternative mode of transport in urban centers was prompted by the high cost, bad state of roads and others inevitable transport service provisions which impacted negatively on economic activities and the relative immobility of the urban populace. Of particular interest is the fact that increasing demand for public transport has been able to match the level of provision of transport services (Gbadamosi, 2006).

The use of motorcycle for urban transportation is not a new phenomenon in Nigeria. It has been commonly used as intra-city urban and rural transport services in riverine areas of the country for over three decades. It has also served as the common mode of inter-rural and rural-urban transport in the dispersed settlement of the eastern states and areas where the conventional public transport system service was not available according to Ogunsanyan, and Galtima, (1993). Okada riding is a popular business and it is commonly used by members of the public. Its role in the Nigeria society cannot be over emphasized. This is because of their low cost of purchase, fuel efficiency and ability to travel on roads that cars 
cannot easily get to (Sandow, 2008). Movement pattern changes with the geographical area and varied employment opportunities of residents (Sandow, 2008; Nivalainen, 2010) as geographical context and culture have defined gender in transportation within such area.

From 1970, social structure had changed up to a great extent. Women started joining the labour market. This creates a scope of research for many researchers. Male and females, somewhere, showed separate types of commuting behavior in United States and Europe(Hanson and Hanson, 1980; Nivalainen, 2010). Women continue to exhibit shorter commute time distances than men. Gender perhaps, have become an issue in contemporary commuting within most urban centers of Nigeria. Gender as used in this context refers to the culturally specific pattern of behavior either actual or normative which may have attached to sexes. It distinguishes between feminine and masculine (Andrew 1982, Oppong\& Abu 1987). This is so since most Okada operatives in most urban centers tends to select who they choose to carry in terms of gender linage. Thus, the choice of motorcycle to carry passenger tends to favor men. This makes women gender-biased by the operators, a basis for the analysis of gender preference of commuter by Okada operatives in Auchi, Estako-west local government area of Edo state with the aim of analyzing the gender preference of commuters among Okada riders in Auchi.

\section{The Study Area and Methodology}

Auchi, an emerging Business District, is located in Estako West, Edo State, Nigeria. The area was predominantly residential in nature with some complementary commercial service places such as school, market, shops, playground and religion centers, until recent time when the area started witnessing transitional use in land. (Asunogie, Momoh Al-Hasan and Ahmed, 2017).As a headquarter of Etsako-West LGA and Edo north region, Auchi is located in the savanna region of south Nigeria, it is unique and lies along the main intersected linking the Northern Part of the country with about $339 \mathrm{~km}$ to Abuja the federal capital territory and about $136 \mathrm{~km}$ to Benin City

For this study, the research design used was strictly survey and observatory approach with a research population of Okada riders in the area estimated to be about $(10,000)$ according to a field work by Edo State Commercial Bike Riders' Association (ESCOBRA), 2019. 486 respondents were sampled for this study using a simple random sampling technique for data collection through questionnaire administration on the operators of Okada.

\subsection{Transportation, Motorcycle -Taxi and Gender: Review of Literatures}

Transport is an important element in economic development and it affords the social and political interaction that most people take for granted (Button \& Hensher, 2001eds). The provision of transport infrastructure has grown extensively across the globe through a range of networks of modes which undergone technological improvements cutting across the motive power, the tracks as well as the means which serve as compartment for passengers and goods. It is also a key player in the transfer and distribution of goods from the input points through the manufacturing line to the customers (Badejo, 2002). Mumby (1968) also highlighted that transport was there since early time of civilization.

Needless to say, transports are very important for promoting the infrastructure of the companies and eliminating poverty. It also enhances the concept of equality. According to Catalina (2015), it improves the conditions of the economy. It smoothes the supply of goods, connects people and checks the continuous opulence of society. Like men, women are equally important for economic growth. Hence an investment with consideration to gender dimensions has potential to bring success and improvement. According to Edmondson (2011), many things need to be considered while designing transport keeping in mind gender perspective. These include needs for travels, outline, main concern, penchant, protection measures.

Expansion of transport network can facilitate many positive impacts on women's and men's lives by increasing access to market for resource and products, and facilitating civic participation. However, inequitable distribution of benefits from improved transport exacerbates existing gender and income disparities (World Bank, 2011). For Jean-Paul (2017), transports are creating social opportunities. On the basis of the foregoing, this paper examines the analysis of gender preferences of commuters amongst Okada operators in Urban Auchi.

\section{Emergence of Motorcycle as Public Transport in Nigeria}

Urban transportation is very important connecting many lands which are arranged in a dispersed way. According to Litman (2012), technology, demand, economy is contributing heavily.

Challenges become severe when improper policies and planning are present (Fadare \& Ogunsanya, 1989; Olufemi \& Oluseyi, 2007), route inadequacy and increasing use of personal mobility also creates huge problem (Torres, 2001). propoor and gender sensitivity transport scheme also create huge problem (Peters, 2001; Olufemi \& Oluseyi, 2007). Many environmental problems also restrict smooth implementation of transport facilities (Dragu, Roman, \& Roman, 2013; Oyesiku, 2001). Improper quality also was causing huge problem (Kumar, 2011).

From 1987 to 1993 the purchasing power of the government faced huge problem due to global economic recession and the fall-out of the Structural Adjustment Program (SAP). Buses and taxis of Nigeria has to be replaced by the government up to a great extend (Oyesiku \& Odufuwa, 2002). These authors also stated that motor cycle is a very common mode of transportation in Nigeria for long period of time. It was very much useful for inter-city transportation in most river line areas of the country.

As per Adeniji (1987), furing mid of 1980s, many companies were incurring loss due to inadequate bus transportation. Capacities were not properly utilized. Many spare parts of bus were not available. Government was showing interest of making investment (Oyesiku, 1996) but the problem was not solved. In spite of great demand transportation were not improvedin urban. 
Under this situation, motorcycle has become very popular transportation medium (Fasakin, 2001).

Many West-African states also used motorcycle as a part of public transport like Nigeria. There were some reasons behind adopting motorcycle.

- Bus, ferries and taxis in many cases not able to fulfill the demand. They often run in over load mode and caused problem to common passengers. Moreover, motorcycle, is able to provide door to door service, which is not at all possible for bus, ferry and taxis. Motorcycle has not any specific public route or bus stop.

- As per a study conducted by Torres (2001), almost sixty percent of the road was very un-maintained and was in poor condition. This made a huge problem for buses and taxis to travel. Compared to this motor cycle took extra advantage and travelled through this road.

- Economic conditions had decreased the purchasing power of the people up to a great extent. Hence, it was not possible for common people to invest money and purchase their own personal vehicle. In this situation. Motorcycle, as a public transport improved the situation up to great extent.

- Motorcycle acted as a safe transport over poor, bad roads. It also worked within bad traffic.

- No such strict policy was formulated to operate motorcycle. Hence, it became easy to afford this transport by secondary and university graduates as operators, who were largely unemployed due to don-economic situation.

- Many people involved as operator of the motorcycle as a way of temporary employment.

Hence it was very proper for motorcycle operators to enter in transport industry as a public transport. It was able to fill the high demand for public transport (Oyesiku\&Odufuwa,2002).

\section{Gender and Mobility}

Here, the term gender stands for specific pattern of behavior in terms of both actual and normative (Andrews 1982; Oppong \& Abu 1987). Many studies have shown different behavior on the basis of gender. Various demographic factors like age, income, perception, time, distance also shows different behavior (Oyesiku \& Odufuwa, 2002). As per the report of World Bank (1990), countries are changing transportation related information continuously. A huge research gap has been seen regarding transportation and women. In developing countries very few researchers are working on it. But in some developed countries researchers are viewing gender issue as a very important element of transportation planning (Oyesiku \& Odufuwa, 2002). Many studies are suggesting many things like home-to-work trips.

Apart from economic variable like income, many non-economic variables like number of kids, marital status also affecting the transport related decisions. Many researches have highlighted about many constraints like "societal" and "physical" constraints (Peet \& Watts, 1996). Mobility and activity patterns are very important to consider in case of physical constraints or challenges.

Mobility is an issue that is gendered both ways. On the one hand, mobility determines women's and men's access to participation in society; On the other hand, Women's and men's mobility is determined by gender role and inequalities (Duchene, 2011). According to him, if people access to mobility is hampered, they will experience difficulties in accessing education, training, and the labor market. Mobility enables economic participation. Without a reliable means of transport, they cannot go to the library, participation in leisure activities or meet their friends and family. Mobility encourages social and cultural participation and lacking mobility they cannot go to meetings or demonstrations, vote or lead an effective election campaign. Mobility allows political participation. Women's travel pattern is different from men's, and these different is characterized by deep and persistent inequalities. Within any given urban settings, women have inferior access to both private and public means of transport while at the same assuming a higher share of their household's travel burden and making more trips associated with reproductive and caretaking responsibilities (Deike, 2013).

Around the world, gender and transport issues are grounded in broader gender inequalities in access to land, labor, financial, and product markets, the gendered division of labor, and associated time poverty (World Bank, 2011). Men and women play multiple roles (productive and unproductive, and the community management, but men generally focus on single productive role and play other sequentially.

\section{Mobility in Household and Women}

Due to car ownership, movement among households has increased up to a great extent since 1945. As per Oyesiku \& Odufuwa (2002), women and men show significant different behavior towards access of cars. Majorly women are not having any car. Women having kids, are facing serious problem of transportation. It is very difficult for them to switch public for private transport suddenly.

Many transportations like motorcycle, creates discomfort for many women (Oyesiku \& Odufuwa, 2002: Uteng, 2011). Society and family often impose many restrictions to women for going out and movements.

Every society has some sort of gender biasness. However, now-a-days women influence many public affairs(De Rivera, and Darío 2007).

The inter-link between gender relations and cultural constraints as it affects the transportation sector has continued to interest researchers as seen in the works of Fernando and Porter (2002); Ubogu, (2006), Oni and Okalawon, (2010). Despite, the significant progress women have made in almost all areas of public life, the issue of public transportation continues to be sore point regarding gender equality. Women's fundamental right to freedom of movement continues to be compromised by harassment from men. Mobility is the prerequisite to accessing goods and services, such as health, jobs, education and leisure. Women face more restrictions to mobility, and their travel patterns differ from those of men. This is largely based on the double or ripple burden they carry, juggling care and reproductive roles with income generating activities. Indeed, the perception of security between men and women is quite different, it also varies significantly between different women of differing socio-economic status, race, age, education and cultures. People also 
change their opinion about the same service to the same destination according to the same time of day (Heather, 2018). Women encounter violence and harassment when they are using public space in general and public transport in particular. Gender-based violence is an umbrella term for any harmful act that is perpetrated against a person's will (Heather, 2018). A woman or man who is single, married with no children, or married with children, etc. will have different transport needs and these needs will change as they enter different stage in life according to Mark, (2017). It is clear that as household composition changes, so do the travel requirements. This is especially the case when children come along, and both men and women travel behavior changes, with women usually taking up extra transport burden especially when the children are young.

\section{Findings}

\subsection{Basic Socio-demographic Information of Respondents}

The research revealed that the operators of Okada as a public taxi mode are wholly male, $(100 \%)$ with varied age categorization. About Forty percent (40.7\%) of the population were between $28-37 \mathrm{yrs}, 21.4 \%$ of the population were 38 $47 y r s$ and $37.9 \%$ of the population were between 18-27yrs. Majority of the riders are married with distributions as $53.5 \%$ married, $32.9 \%$ single, while $13.6 \%$ were divorcee. Educationally, $56.0 \%$ of operators had no informal education, $30.5 \%$ had primary education and $13.5 \%$ had secondary school education.

Some of the respondents are engaged in other vocations besides the business of Okada with $42.8 \%$ of the respondents fully employed in the business, $32.5 \%$ were primarily students, $15,2 \%$ being civil servants and artisans. Socio-ideologically, $52.7 \%$ of the respondents were Christians while $47.3 \%$ where Muslims. Hausa/Fulanis was the dominant tribe among the respondents with $13.6 \%$ being Igbos, $15.2 \%$ being efik/Akwa-ibom, $32.5 \%$ being Edo/Delta and $38.7 \%$ being Hausa/Fulanis;

\subsection{Income and Gender Preference Information of Respondents}

The information generated from the survey showed that, majority of the respondents earned between $\mathbf{N} 1000$ \$5000 daily with $13.6 \%$ earning $\mathbf{6 0 0 0}$ - 11000 while $86.4 \%$ earned between $\$ 1000$ - $\mathbf{N} 5000$.Some of the respondents work between 7 - 9 hours daily with $4 \%$ working between 13 - 15 hours, 11\% working between $10-12$ hours, $42 \%$ working between $7-9$ hours, $27 \%$ working between $4-6$ hours while $16 \%$ work between $0-3$ hours.

Most of the respondents preferred to carry single passenger with $44.4 \%$ preferring two passengers per trip, $9.5 \%$ preferring multiple passengers per trip and $46.1 \%$ preferring single passenger per trip. Respondents agreed that women had the highest form of patronage for their business with $49 \%$ of patronage coming from females, $30 \%$ of patronage coming from both sexes while $21 \%$ of patronage comes from males. a high percentage of respondents preferred to carry the male gender with $28 \%$ preferring to carry any of both sex discrimination, $25 \%$ preferring to carry only females, and $47 \%$ preferring to carry only males.

\subsection{Influence of Preference Information of Respondents}

Analysis of survey revealed factors influencing the rider's preference of commuter by gender. willingness to pay more was more associated with men without any level of biasness with $43.7 \%$ of the passenger willing to pay more being male, $31.4 \%$ of the passenger willing to pay more being female while only $24.9 \%$ of both sex willing to pay more with some level of biasness; the length of the distance to cover is on the male patronage with $53 \%$ of men covering more distance, $39 \%$ of female covering more distance while only $8 \%$ of both sex covering more distance. Neatness was an underpinning factor to the degree of patronage with $32 \%$ or riders washing their uniforms on a daily basis, $63 \%$ washing on a weekly basis and about $5 \%$ washing on a monthly basis.

The females demanded for specialized or home call services with $23.5 \%$ of male demanded for home call, $44 \%$ of female demanded for home call and 32.5\% of both sexes demanded for home service without biasness. Another discriminant factor was the luggage of passengers as $76 \%$ of female have extra loads while only $24 \%$ of male had extra loads to carry for any trip.

Obese or overweight was another issue with $71 \%$ of female always overweighed and $29 \%$ of male overweighed. The study also revealed that male possess more risk to operators at night with $35.8 \%$ of female possessing risk, $45.7 \%$ of male possessing risk while $18.5 \%$ of both sex possess risk at night; on the basis of preferred patronage, the study revealed that body contact as a basis for patronizing male accounted for $9 \%$, Cleanliness of the commuter accounted for $37 \%$ while Sweet chat/talk accounted for $54 \%$. Overweight according to the study was why $72 \%$ of respondents avoided women while only $28 \%$ carried any of both sexes even with the weight on the high side

\subsection{Discrimination Information of Respondents}

The study revealed that $53.3 \%$ of respondents strongly agreed, $15.1 \%$ Agreed, $22.1 \%$ Disagreed and $9.5 \%$ strongly disagreed that sex was the basis for discrimination. $24.7 \%$ of respondents strongly agreed, $\%$ Agreed, $74.9 \%$ and $0.4 \%$ disagreed that trip distance was the basis for discrimination. $19.3 \%$ of respondents strongly agreed, \% Agreed, $57.2 \%$ and $23.5 \%$ disagreed that trip route was the basis for discrimination. $44.4 \%$ of respondents strongly agreed, $\%$ Agreed, $46.1 \%$ and $9.5 \%$ strongly disagreed that the time of the day was a basis for discrimination.77.0\% agree,13.6\% strongly agree, while $9.5 \%$ disagree that respondents discriminate commuter on basis of luggage/load. $71.2 \%$ agree, $23.0 \%$ strongly agree, while $5.8 \%$ agree that the respondents discriminate commuter on basis of weight/obesity; that $56.8 \%$ strongly agree, $42.8 \%$ agree, while $4 \%$ disagree that discrimination is on basis of payment of service. 


\section{Summary of Findings}

\subsection{Summary}

From the study, it clear that all respondents were male, only $37.9 \%$ of the population were below 27 years old, $53.5 \%$ were married, a good number of the riders are not educated with $56.0 \%$ having informal education, only $42.8 \%$ fulltime Okada riders, $52.7 \%$ were Christians and Hausa/Fulanis was the dominant tribe among the respondents with $38.7 \%$ of the respondents. The survey showed that $86.4 \%$ earned between $\mathbf{N} 1000-\mathbf{N} 5000,42 \%$ worked between $7-9$ hours daily, $46.1 \%$ preferred single passenger per trip, $49 \%$ of patronage came from females but $47 \%$ preferred to carry only males. It also revealed that a lot of factor influence the rider's preference. These included the willingness to pay more that is associated with men without any level of biasness, the length of the distance which was more for males, neatness as an underpinning factor to the degree of patronage, specialized or home call service associated with most females, extra load associated with most females, interference on decision making situations associated with most females, overweight associated with most females, risk to riders at night associated with men, body contact or lost associated with females, Sweet chat/talking associated with females among others. From the revelations, the following where the agreement/disagreement of the basis for discrimination. This include basis of Sex, Trip distance, Trip route, Time of the day, Extra luggage/load, Weight or Obesity and Payment for service rendered.

\section{Conclusion and Recommendation}

Based on the findings above, it is safe to conclude that okada riders in Auchi are all men that are mostly married with little or no formal education comprising of different ethnic nationality within the country and are married, with daily earnings between $\mathbf{N} 1000$ - $\mathbf{N} 5000,42 \%$ under the working time between 7 - 9 hours daily, they work so hard to earn a living. This study hereby concludes also that there is clear evidence of preference against females by okada operators/riders but this is due to underpinning factors ranging from weight, extra luggage among others (see findings for details).

Based on the conclusion above, it is recommended that:

- Environmental and sustainability issues, as well as gender perspective need to be fully integrated into all transport related policy-making in all department at all levels on a regular and proactive basis.

- Government should introduce participatory, inclusive transport planning methodologies in other to incorporate the social gender of transport and travel need. This is because Gender budget analysis is an important tool of engendering micro-economics analysis that should be conducted to provide information about how much women and men power engaging in operation.

- There is a need for more inclusive gender sensitive transport system in the study area. This is possible through the encouragement of more public investment in intra-urban transport service to accommodate all genders

- There is utmost need for Government at this level to encourage inter-modal transport in the study area in order to address the issue of gender bias in intra-urban mobility in the study area followed with consistent and aggressive enlightenment against female gender discrimination with possible sanctions on offenders where there is proven evidence through adequate legislation.

\section{References}

i. Adeniji, K. (1987), "Para-transit modes in Nigeria Cities: Problems \& Prospects", international Quarterly of Urban Policy, Butterworth \& Co. (Publishers) Limited, London.

ii. Andrews A. C. (1982). Towards a Status of Women Index. Professional Geographer, Vol. 34 (1) 24 - 31.

iii. Asunogie, O.F, Momoh, S., Al-Hasan, A. Z. And Ahmed, M. B. (2017). Urbanization and Landuse Conversion: A Survey-Based Study. The $7^{\text {th }}$ National Conference of the School of Environmental Studies, Federal polytechnic, Nasarawa, $12^{\text {th }}-14^{\text {th }}$ July.

iv. Badejo, B.A. (2002). The Dilemma of emerging urban public transportation in Nigeria.LASU Journal of Social Science, Vol 4.33 - 44.

v. Button K.J. and Hensher A. (eds), (2001), Handbook of transport systems and traffic control paragon. London, UK

vi. $\quad$ Catalina C. (2015). Gender Equality in Transport Is Good for Business: Suggestions to Ensure Successful Gender Mainstreaming. Published On Transport For Development.https://blogs.worldbank.org/transport/genderequality-transport-good-business-suggestions-ensure-successful-gender-mainstreaming

vii. $\quad$ Cervero, R. (1991). Congestion Relief: The Land Use Alternative. Journal of Planning Education and Research https://doi.org/10.1177/0739456X9101000209

viii. Cervero, R. and Golub, A. (2007). Informal transport: A global perspective. Transport Policy, Volume 14, Issue 6, pp. 445-457.

ix. De Rivera, J. and Darío P. (2007). Emotional Climate, Human Security, and Cultures of Peace. Journal of Social Issues, https://doi.org/10.1111/j.1540-4560.2007.00506.

x. Deike P. (2013) Gender and Sustainable Urban Mobility. Thematic study prepared for Global Report on Human Settlements.

xi. Dragu, V., Roman, E.A. and Roman, V.C. (2013). Quality assessment in urban public transport. Theoretical and Empirical Researches in Urban Management. 8. 32-43.

https://www.researchgate.net/publication/289732784 
xii. Duchene, Chantal (2011). Gender and Transport. Discussion Paper No. 11. International Transport Forum and OECD, Paris.

xiii. Edmondson, A. C. (2011) "Strategies for Learning from Failure”. Harvard Business Review Vol. 4; 89 - 99

xiv. Edo State Commercial Bike Riders Association, (2019).A Register of Commercial Bike Riders in Auchi and Environs, ESCOBRA. Unpublished.

xv. Fadare, S.O. and Ogunsanya, A.A. (1989)."Planning without data: the example of the Nigerian Urban transport planning situation, studies in environmental design in West Africa, University of tieste, Italy, Vol. 8. Pg. 57-66.

xvi. Fasakin, J.O. (2001). Some factors affecting daily profits of commercial motorcycles in Akure, Nigeria. Transport policy Vol. 8. 63-69.

xvii. Fernando S and Porter G, (2002). Balancing the Load, Gender Issues in Rural Transport. London and New York. xviii. Gbadamosi, K.T. (2006). The Emergency of motorcycle in urban transportation in Nigeria and its implication on traffic society". Center for transport studies. Olabisi Onabanjo University Ago-Iwoye, Nigeria.

xix. Hanson S, \& Hanson, P. (1980).Gender and urban in Uppsala, Sweden. Geographical review vol. 70, pg. $291-99$.

xx. Heather A., (2018). Independent consultant in sustainable transport: A source book for policy makers in developing cities, vol. 7; 44 - 51

xxi. Jean-Paul R. (2017). New York 4thedition (The geography of Transport System Routeledge, 440 pages. ISBN 978-1138669574.

xxii. Kumar, A., (2011). Research and writing skills. New York, Lulu press (978-1-4466-0560).

xxiii. Litman, T. (2012), towards more comprehensive and multi- modal transport evaluation, VTPI (www.vtpi,org) at www.vtpi org/com evaluation .pdf.

xxiv. Mark, L (2017): Daily Immobility in Slums. A female perspective from the villa 20 in Buenos Aires. Master's thesis. Technische University of Berlin.

xxv. Mumby, D. L. (1968): Transport: Selected Readings. Harmondsworth: Penguin

xxvi. Nivalainen, S. (2010).Essays on Family Migration and Geographical Mobility in Finland. https://www.researchgate.net/publication/265264180

xxvii. Ogunsanya, A. A. \& Galtima, M. (1993). Motorcycle in public passenger transport service in Nigeria: a case study of Yola Town. In S. G. Ikya (ed.), Urban passenger transportation in Nigeria: 190 - 207. Ibadan: Heinemann Educational Books (Nig.).

xxviii. Olufemi O.B and Oluseyi, M.S. (2007). The urban poor and mobility stress in Nigerian cities. Environment Research journal 1:1-8.

xxix. Oni, S.I. and Okanlawon, K.R. (2010)."Transportation Education in Nigeria in p. Ikulayo(ed).Exploring the multifaceted dimensions in exercise and sports psychology. Olu-Akin, published: Ibadan, Nigeria pg. 106-118

xxx. Oppong, C \& Abu, K (1987).A handbook for data collection and analysis on seven roles and status of women. ILO: Geneva

xxxi. Oyesiku 0, and Odufuwa B (2002). Gender Perspectives in Travel Behavior of Motorcycle Passengers in Nigeria Intermediate Cities. In CODATU X Conference Proceedings on Urban Mobility for All.Zeitlinger, Netherlands.

xxxii. Oyesiku, O. K. (2001). City poverty and emerging mobility crisis the use of motorcycle as pub-lic transport in Nigerian cities. Paper presented at the 9th World Conference of Transport Research, Seoul, 22 - 27 July.

xxxiii. Oyesiku, O.K. (1996). : Regional analysis of transport infrastructure and socio-economic factors of Nigerian development. Research for Development 11(12), 112-128.

xxxiv. Peet, R. \& Watts, M. (1996). Liberation ecologies: environment, development, social movement. London: Routledge

xxxv. Peters D (2001). Gender and Transport in Less Developed Countries; A Background Paper in Preparation for CSD-9. London, Paper Commissioned by UNED Forum.

xxxvi. Sandow, E. (2008). Commuting Behaviour in Sparsely Populated Areas: Evidence from Northern Sweden. Journal of Transport Geography, 16, 14-27. http://dx.doi.org/10.1016/j.jtrangeo.2007.04.004

xxxvii. Torres M.J, (2001). Road maintenance policies in Sub-Saharan Africa: unsolved problems and acting strategies. Transport Policy 8 vol. (4): 257 - 266.

xxxviii. Ubogu, A.E (2006). Telecommunication and intra-urban trip pattern in Zaria transport, vol 23, $161-166$.

xxxix. Uteng, T. P. (2011). Gender and Mobility in the Developing World. Gender Equality and Development, World Development Report,

https://siteresources.worldbank.org/INTWDR2012/Resources/7778105-1299699968583/77862101322671773271/uteng.pdf

xl. World Bank Report, (2011) (making transport work for women and men challenges and opportunities).

xli. World Bank. (1990). Nigeria: Urban Transport in Crisis. Lagos: World Bank West Africa Department Infrastructure Division. 